\title{
EXPERIMENTAL STUDIES OF LOAD CAPACITIES OF DOUBLE-LAYER SHORING SYSTEMS
}

\author{
Jui-Lin Peng ${ }^{1,}$, Pao-Li Wang ${ }^{2}$, Ying-Hua Huang ${ }^{3}$ and Tsung-Chieh Tsai ${ }^{3}$ \\ ${ }^{1}$ Prof., Dept. of Constr. Engrg., \\ Yunlin Univ. of Sci. and Technol., Douliu, Yunlin, 64002 Taiwan, China. \\ ${ }^{2}$ Ph.D. Student, Dept. of Graduate School of Eng. \& Tech., \\ Yunlin Univ. of Sci. and Technol., Douliu, Yunlin, 64002 Taiwan, China. \\ ${ }^{3}$ Assistant Prof., Dept. of Constr. Engrg., \\ Yunlin Univ. of Sci. and Technol., Douliu, Yunlin, 64002 Taiwan, China. \\ *(Corresponding author: E-mail: pengjl@yuntech.edu.tw)
}

Received: 26 January 2009; Revised: 17 August 2009; Accepted: 18 August 2009

\begin{abstract}
The most common shoring system used in mid-headroom buildings in Taiwan is the double-layer shoring system made of wooden shores or adjustable steel-tube shores or a combination of both. This study identifies the causes of shoring system collapse and proposes solutions that ensure the safety and stability of double-layer shoring systems. The test results show that the load capacity is the largest for a double-layer shoring system set by the lateral supports along the four sides. In terms of connections of horizontal stringers, the failure models of "single overlap" and "double overlap" are extremely similar. The shoring members in the system tend to move toward the overlap position after loading. The single butt connection is recommended to replace these two overlapping connections in construction sites since the former provides higher load capacity in shoring systems. In terms of the eccentric load, load capacity when shoring arrangements of the top and bottom stories are not directly symmetrical is lower than that of the top and bottom stories with a directly symmetrical arrangement. The load capacity is increased considerably when a shoring system is reinforced with V-shaped inclined braces. The load capacity of a shoring system with a setup combining wooden shores and adjustable steel-tube shores is higher than that of a system reinforced with wooden shores only.
\end{abstract}

Keywords: Adjustable steel tube shore; collapse; double-layer shoring system; load capacity; shoring; wooden shore

\section{INTRODUCTION}

During construction, various temporary shoring structures are utilized to support construction loads on formwork before fresh concrete reaches its designed strength. Such falsework frequently adopts different shoring systems based on different construction site conditions. Construction sites in Taiwan are typically one of three types-low headroom, medium headroom and high headroom - based on different internal clearance heights of buildings. In Taiwan, low, medium and high headroom is defined as headroom smaller then $4 \mathrm{~m}$, between $4 \mathrm{~m}$ and $7 \mathrm{~m}$ and greater than 7 $\mathrm{m}$ respectively.

Two types of shores (Figure 1), wooden shores and adjustable steel-tube shores, are often used at mid-clearance construction sites in Taiwan, mainly because of cost considerations. Double-layer shoring systems made of wooden shores, adjustable steel-tube shores or a combination of both are employed depending on different internal headroom heights of buildings. To construct a double-layer shoring system, horizontal stringers are first laid on vertical shores in a side-by-side manner, and then more vertical shores are installed on horizontal stringers to form a double-layer system (Figure 2). This support structure is nicknamed, "Snake-Melon Shed" in Taiwan; in this study, this system is called, "Double-layer Shoring System." 


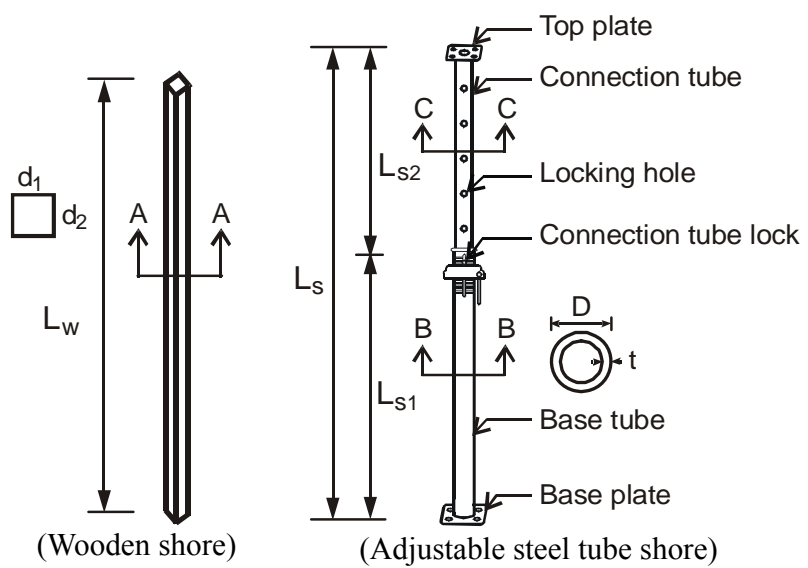

\begin{tabular}{|c|c|c|c|c|}
\hline Cross section & $\mathrm{d}_{1}(\mathrm{~mm})$ & $\mathrm{d}_{2}(\mathrm{~mm})$ & $\mathrm{D}(\mathrm{mm})$ & $\mathrm{T}(\mathrm{mm})$ \\
\hline A-A & 58.82 & 56.295 & - & - \\
\hline B-B & - & - & 60.14 & 2.21 \\
\hline C-C & - & - & 48.04 & 2.31 \\
\hline
\end{tabular}

Figure 1. Dimensions of Wooden Shore and Adjustable Steel Tube Shore

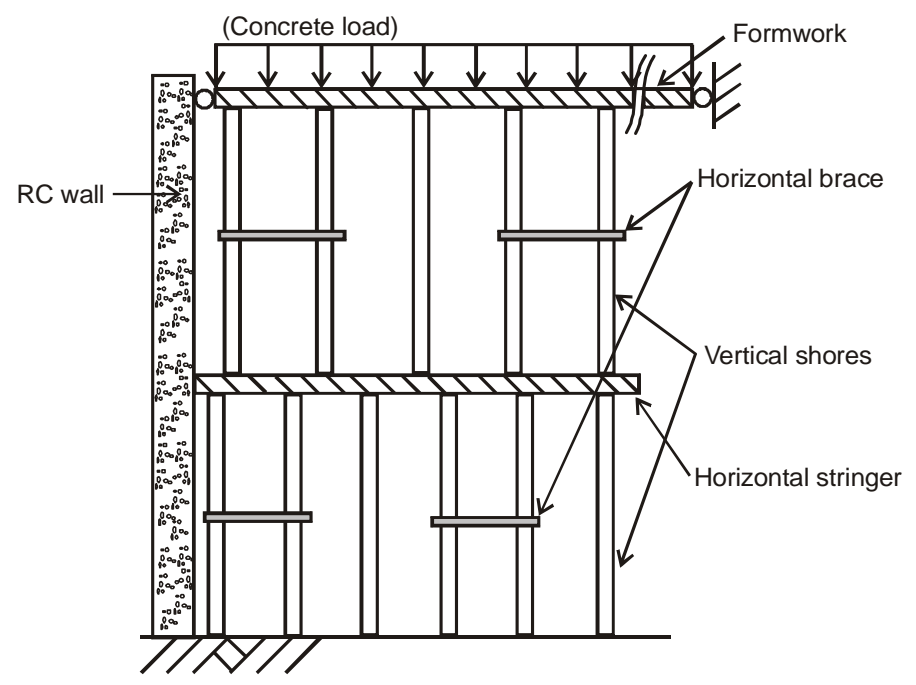

Figure 2. Setup of a Double-layer Shoring System with Horizontal Stringers and Braces

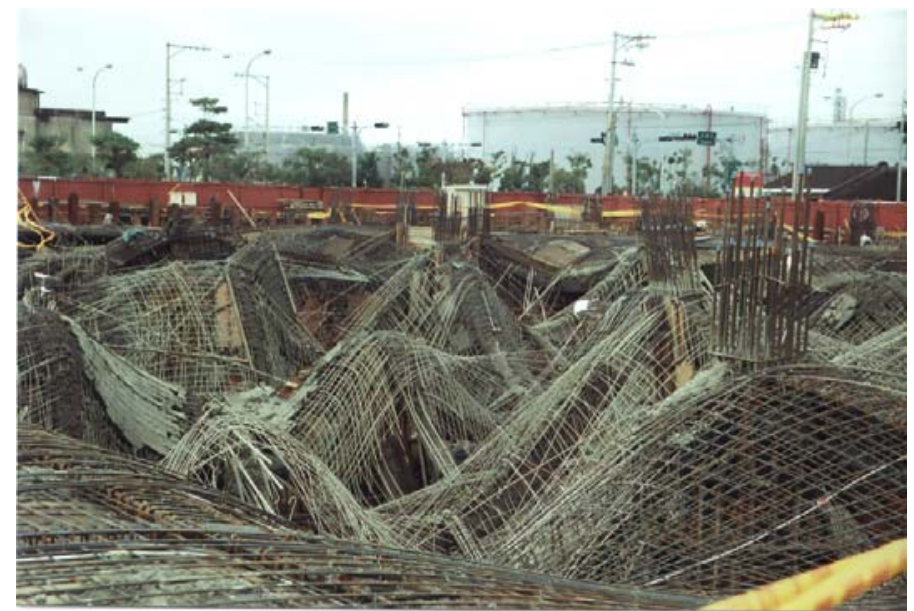

Figure 3. Collapse Scene at Construction Site of Xinzhu Chemical Engineering Warehouse Mall, Taiwan 
Since design specifications in Taiwan do not cover this type of temporary shoring system, workers rely on their experience when setting up such shores. Due to budget constraint, constructors usually use a relatively low-cost double-layer shoring system as falsework, instead of the more expensive steel-tube scaffolding structure. However, the failure of double-layer shoring systems frequently results in collapse, causing casualties and enormous loss of life and property. For example[1] (Figure 3), the collapse of a double-layer shoring system at the Xinzhu Chemical Engineering Warehouse Mall, Taiwan, killed one worker and seriously injured seven others.

Many studies have investigated the structural behaviors of steel-tube scaffolds as falsework. Hadipriono and Wang [2] examined failure causes of temporary shoring systems and concluded that failures usually occurred during concreting. Kao [3] conducted an experimental study on modular units of steel-tube scaffolds using reduced models. Leu et al. [4] calculated the critical loads of shoring systems based on structural dynamic features and the natural frequencies of steel-tube scaffolding structures. Chan et al. [5,6,7,8] proposed a non-linear analysis method for checking of stability. Peng et al. $[9,10,11]$ analyzed construction safety and failure models of scaffolding falsework for high-clearance floors with a headroom exceeding $7 \mathrm{~m}$.

In a study of falsework for multi-story buildings, Mosallam and Chen [12] and El-shahhat et al. [13] obtained notable analytical results regarding shoring and re-shoring. In a study on the effects of wooden shores and adjustable steel-tube shores used in one-layer shoring systems, Peng [14] concluded that the leaning column effect has significant impact on load capacity of one-layer shoring systems. In the study of double-layer shoring systems, Peng [15] numerically analyzed the critical loads and failure behaviors of various shoring systems and established a simplified analytical model. Lemessurier formula [16] was used to calculate system critical load in the study [15].

In the past, studies of falsework generally investigated system critical load and the failure model of steel-tube scaffolding structures, whereas studies of double-layer shoring systems were conducted only for the purpose of analyses. The analytical results obtained required verified via further tests. This study conducts loading tests for double-layer shoring systems in mid-clearance structures to identify the failure models of double-layer shoring systems. Solutions for improving the safety of double-layer shoring systems are based on research results.

\section{RESEARCH OBJECTIVES AND SIGNIFICANCE}

This study explores the load capacities of double-layer shoring systems via experimental tests to identify collapse causes and provide improvement solutions to ensure construction safety. Test configurations of double-layer shoring systems are based on actual setups at construction sites in Taiwan. The highlights of this study are as follows.

\section{$2.1 \quad$ Effect of Lateral Supports}

Buildings typically have openings such as entrances, windowsills or courtyards. During construction, horizontal stringers of double-layer shoring systems often cannot be linked by supports connected to reinforced concrete walls or columns. Additionally, when constructing such structures as gas stations and pavilions, the shoring systems are normally either laterally supported only on one side or unsupported. This study explores the effects of lateral supports on load capacity of double-layer shoring systems. 


\subsection{Effect of Joint Forms of Horizontal Stringers}

When a building construction area is large, a method of connection to install an entire shoring system is needed. When setting up double-layer shoring systems on construction sites, workers often mount horizontal stringers on the top of bottom-story shores and do not pin the joint layer of horizontal stringers with nails for the sake of convenience. This study explores the effects of different joint forms of horizontal stringers in double-layer shoring systems.

\subsection{Effect of Horizontal Braces}

This study explores the effects of horizontal braces on load capacity of shoring systems by simulating practical bracing reinforcement on actual construction sites. From the viewpoint of structural stability, the collapse of entire double-layer shoring systems is commonly caused by lateral movement of horizontal stringers. The "leaning column effect" is likely when horizontal stringers move laterally [16]. At most construction sites, double-layer shoring systems are reinforced with "lateral braces." Whether or not this bracing reinforcement enhances the stiffness of wooden shores is worthy of investigation.

\subsection{Effect of Eccentric Loads on Shores}

Axial force transfer will be interrupted in double-layer shoring systems that have vertical shores for the top and bottom stories that are not directly symmetrical. Thus, horizontal stringers between the top and bottom stories bear the vertical force directly transferred from top-story shores, resulting in bending failure of horizontal stringers and likely leading to failure of the overall shoring system.

When shores are set up in a double-layer shoring system on construction sites, workers are not expected to set the top- and bottom-story shores on the same axial line. This study investigates the load capacities and failure models of double-layer shoring systems with eccentric loads and analyzes whether axial force indirectly transferred significantly impacts load capacity.

\section{$2.5 \quad$ Effect of Inclined Boundaries}

Designers in some cases use slant planes for esthetic considerations (e.g., car ramp lanes and auditoriums). In this case, the boundaries of a double-layer shoring system may be planes inclined at various angles. This study explores the effects of inclined boundaries on the load capacity of double-layer shoring system via laboratory tests.

\subsection{Effect of Combined Shores}

Due to budget constraints and the available length of shores, many double-layer shoring systems are set up in such a manner that the bottom story is made of adjustable steel-tube shores, while the top story is made of wooden shores. Through testing, this study investigates the difference in load capacity between double-layer shoring systems using both wooden shores with adjustable steel-tube shores and those using wooden shores only.

\subsection{Effect of Different Reinforcements}

Most workers strengthen shoring systems on construction sites based on experience; but they may not know the load capacity after reinforcement. This study explores the effects of various reinforcements for double-layer shoring system based on a comparison with existing reinforcements on construction sites. 


\section{MATERIAL PROPERTY AND TEST PLAN}

\subsection{Material Property}

The wooden shores and adjustable steel-tube shores selected for this study are commonly used in Taiwan. The material properties of the shores are as follows. (1) The wooden shores are made of Kapur. Their average cross section is $5.6295 \times 5.882 \mathrm{~cm}$; average static bending elastic modulus (equivalent to Young's modulus of elasticity) is $1.247 \times 10^{6} \mathrm{~N} / \mathrm{cm}^{2}\left(127,163 \mathrm{kgf} / \mathrm{cm}^{2}\right)$. (2) The properties of the adjustable steel-tube shores are as follows. The average diameter and thickness of the base tube are $60.14 \mathrm{~mm}$ and $2.21 \mathrm{~mm}$, respectively. The average diameter and thickness of connecting tubes are $48.04 \mathrm{~mm}$ and $2.31 \mathrm{~mm}$, respectively (Figure 1). Young's modulus of elasticity is $2.11 \times 10^{7} \mathrm{~N} / \mathrm{cm}^{2}\left(2,150,000 \mathrm{kgf} / \mathrm{cm}^{2}\right)$.

\subsection{Test Plan}

Figure 4 shows the definition of in-plane and out-of-plane adopted in this study. The tubes are numbered clockwise as tube 1 , tube $2 \ldots$ to tube 6 (Figure 4). Failure of the double-layer shoring system involves problems of structural stability. To investigate the failure behavior of a shoring system, axial force and lateral displacement are considered two key measurements. The axial force is measured using load cells placed in the fillister between the load holder and oil-pressure piston. Lateral displacement is measured using two rulers set on the horizontal stringers and two theodolites are used to measure the lateral displacements of systems in two directions. Test configurations of this study are as follows.

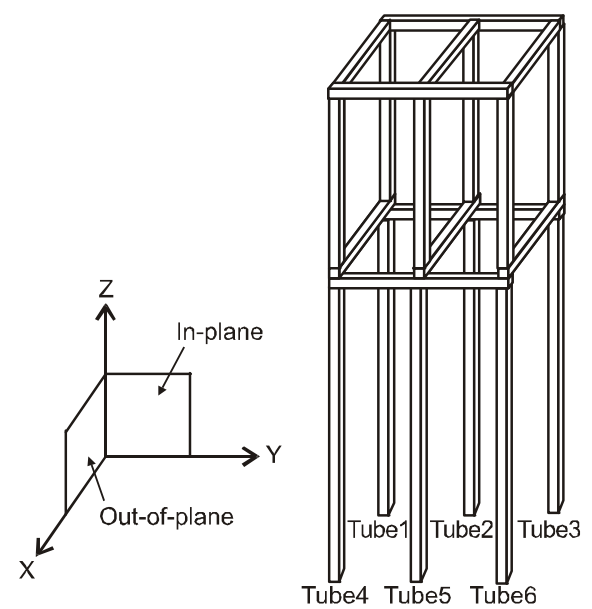

Figure 4. Definition of In-plane and Out-of-plane of Double-layer Shoring Systems

\subsubsection{Isolated wooden shore}

This study investigates the load capacity of isolated wooden shores as a basis for comparisons and for subsequent bearing-capacity tests on double-layer shoring systems. The wooden shores are 3.0 $\mathrm{m}$ long. Load capacity is measured via loading tests that meet the CNS-453 code [17]. However, the top-end boundary conditions of bottom-story shores in a double-layer shoring system are horizontal stringers. This boundary condition likely affects the load capacity of wooden shores. Therefore, the top-end boundary condition is used as horizontal stringers to minimize the real construction conditions. 


\subsubsection{Shoring systems reinforced with lateral supports}

This study conducts tests with various support conditions to identify the effects of lateral supports on load capacity of double-layer shoring systems. Three cases are tested: (A) Double-layer shoring systems with no lateral supports: the double-layer shoring system is set up with 6 wooden shores on both the top and bottom stories. The top shores are $1.8 \mathrm{~m}$ long and the bottom shores are $3 \mathrm{~m}$ long (Figure 5(a)). The shores for the top and bottom stories are placed $60 \mathrm{~cm}$ apart. Horizontal stringers are placed at the joints of the top and bottom stories. Without any lateral supports, the shoring system alone bears vertical loads. The bottom end of the shoring system is placed on concrete floor and the top end is fastened with a horizontal wooden frame to simulate the most common scenario on construction sites. (B) Double-layer shoring systems with lateral supports on two sides: the basic double-layer shoring system is reinforced with lateral supports on the weak axial direction, allowing the system to have lateral displacement in one direction only (Figure 5(b)). (C) Double-layer shoring systems with lateral supports on four sides: the basic double-layer shoring system is reinforced with longitudinal supports and lateral supports on four sides, such that the system bears lateral forces in both directions from supports (Figure 5(c)). To avoid horizontal movement, lateral supports, $60-\mathrm{cm}$ adjustable steel tubes, were connected to the horizontal stringers in the basic shoring system (Figure 5(c)).

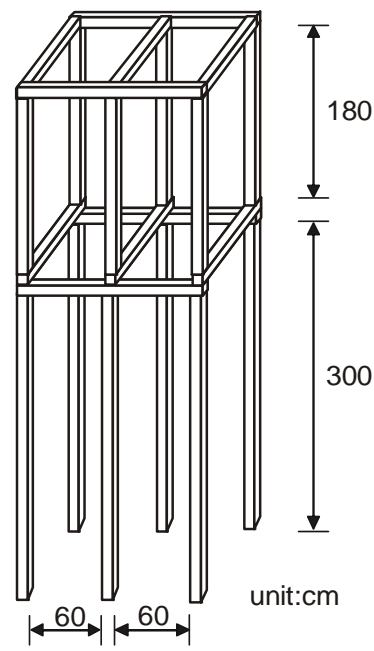

(a) unsupported

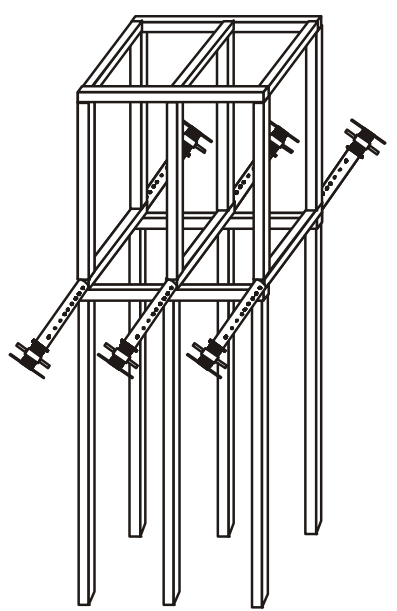

(b) supported on two sides

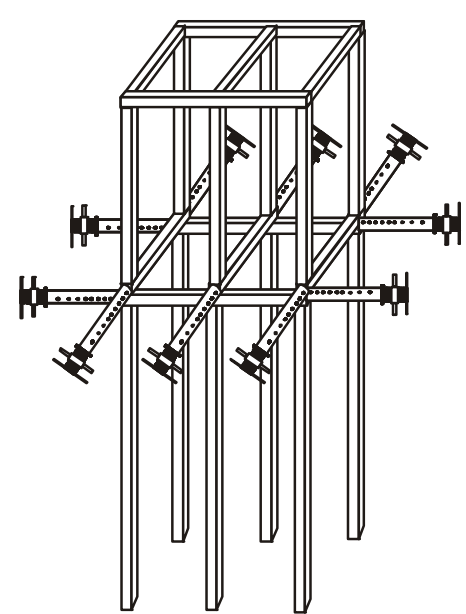

(c) supported on four sides

Figure 5. Arrangements of Double-layer Shoring Systems with Varied Lateral Supports

\subsubsection{Varied connection forms of horizontal stringers}

This study explores the effects of various joint forms for horizontal stringers in double-layer shoring systems. The connection at the joint layer of horizontal stringers can be of two types- "butt connections" and "overlap connections." Three connection configurations for double-layer shoring systems are considered based on typical conditions on construction sites: (A) a single butt fastened with a $30-\mathrm{cm}$ board connected to horizontal stringers (Figure 6(a)); (B) a single overlap without any fastening form connects horizontal stringers (Figure 6(b)); and, (C) double overlaps without any fastening form connecting horizontal stringers (Figure 6(c)) - this is a common joint used for horizontal stringers on construction sites in Taiwan. These three tests are all conducted with lateral supports on four sides. 


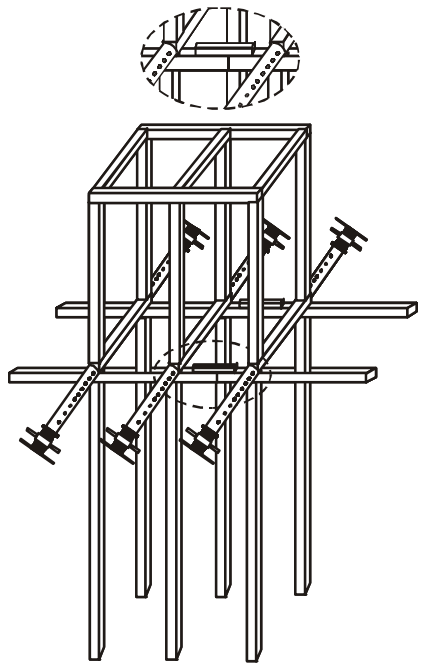

(a) single butt

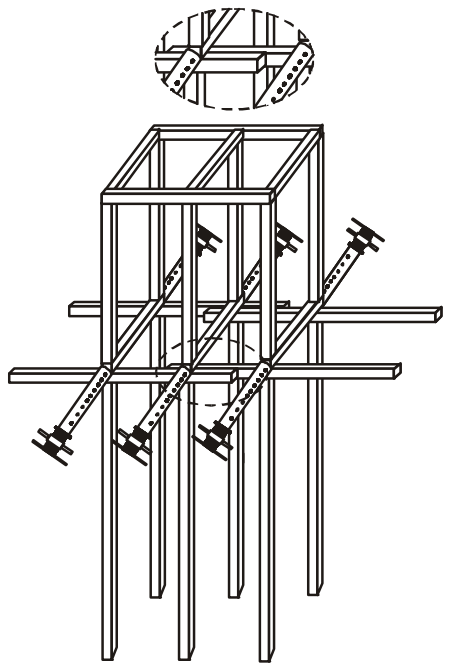

(b) single overlap

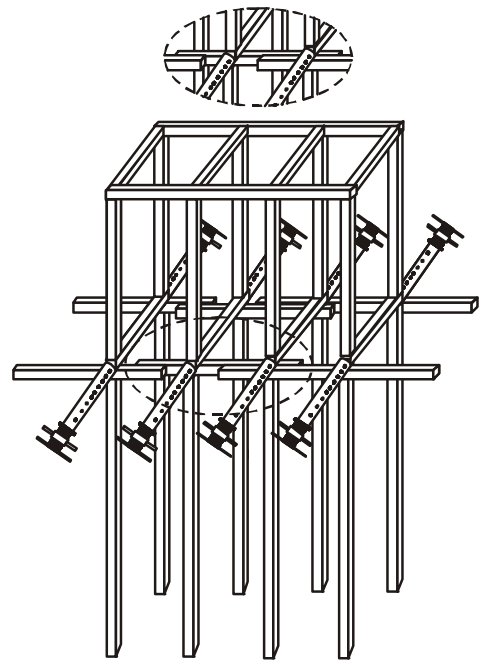

(c) double overlaps

Figure 6. Arrangements of Double-layer Shoring Systems with Varied Connection Forms for Horizontal Stringers

\subsubsection{Shoring systems reinforced with closed-form horizontal braces}

Four horizontal braces form the rectangular hollow to simulate the longitudinal and lateral braces used on construction sites. These horizontal braces are only tied to vertical shores without objects to resist lateral forces. This test investigates reinforcement effects of these horizontal braces. The test is configured by tying horizontal braces to tubes 1,2, 4 and 5 of the bottom-story wooden shores with wires at a height of $1.5 \mathrm{~m}$ above the ground, and setting up lateral supports on the weak plane (Figure 7). The horizontal wooden braces are $80 \mathrm{~cm}$ long, $6 \mathrm{~cm}$ wide and $3 \mathrm{~cm}$ thick.

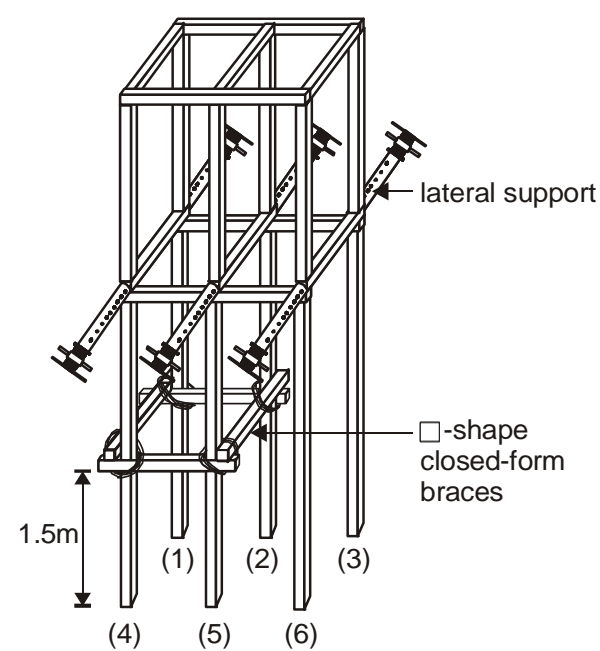

Figure 7. Arrangements of Double-layer Shoring Systems with Horizontal Braces 


\subsubsection{Effect of eccentric loads on shores}

On construction sites, one commonly encounters a situation in which the top- and bottom-story shores are not aligned in double-layer shoring systems. This test is designed to determine whether the load capacities and mechanical behavior of the shoring system are affected when axial force is transferred indirectly. In the test configuration, the top shores of the double-layer shoring system displaced $20 \mathrm{~cm}$ inward and lateral supports are set up along four sides (Figure 8).

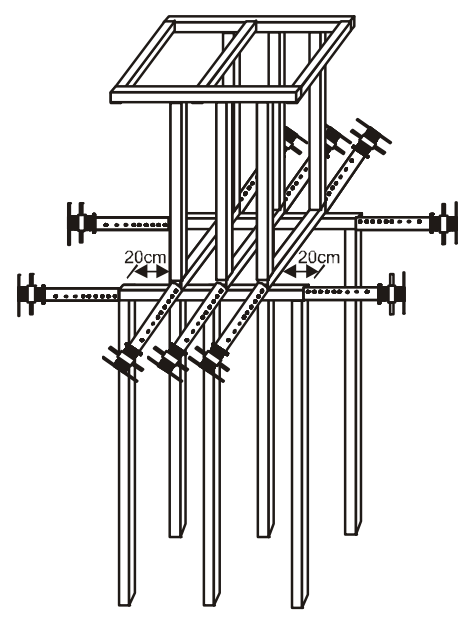

Figure 8. Arrangements of Double-layer Shoring Systems with Indirect Transfer of Axial Forces

\subsubsection{Inclined boundary conditions}

This test examines the effects of inclined boundary conditions on the load capacity of a double-layer shoring system. Two boundary conditions are compared. (A) The top and bottom boundaries of the double-layer shoring system are both plane surfaces (Figure 5(c)). (B) The bottom boundary of the double-layer shoring system is an inclined surface (Figure 9). The inclination angle $\alpha$ of the base is $20^{\circ}$. These two test setups have lateral supports on four sides.

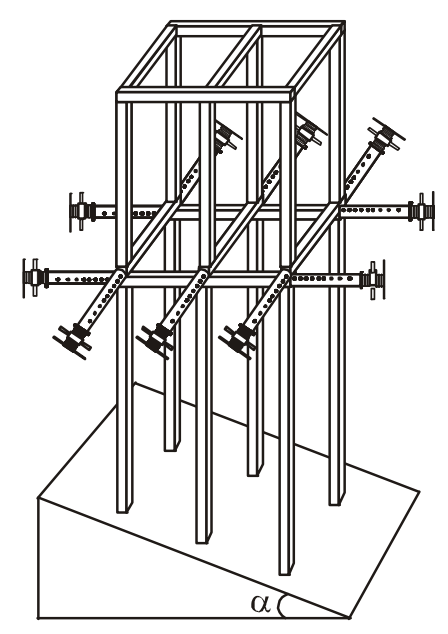

Figure 9. Arrangements of Double-layer Shoring Systems with Inclined $20^{\circ}$ to Ground 


\subsubsection{Combination of wooden and steel-tube shores}

This test assesses the load capacity of wooden shores in a double-layer shoring system (Figure 5(c)). Furthermore, the load capacity of wooden shores and adjustable steel-tube shores combined (Figure 10 ) is investigated. These tests are conducted with lateral supports on four sides (Figures 5(c) and $10)$.

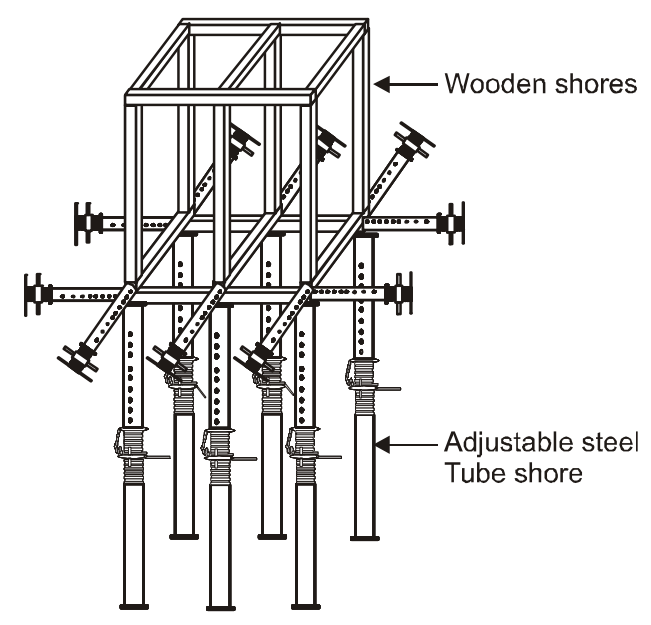

Figure 10. Combination of Wooden \& Adjustable Steel Tube Shores in Double-layer Shoring Systems

\subsubsection{Effect of different reinforced types}

This test compares the effects of various reinforcements on double-layer shoring systems. The following configurations were tested:

(A) Large inclined reinforcement braces were installed on the top and bottom stories. Four wooden shores, two for $3.0 \mathrm{~m}$ and $1.9 \mathrm{~m}$ in length respectively, were used as diagonal braces in the double-layer shoring system (Figure 11(a)). Small woodblocks were inserted into the gap such that the diagonal braces are tight when the length of the wooden shores is inadequate.

(B) Small inclined braces were installed on the top and bottom stories. Four inclined wooden shores, each $72 \mathrm{~cm}$ long, were used to reinforce the double-layer shoring system (Figure 11(b)). The reinforced wooden shores were setup diagonally with an inclination angle $\theta$ of $30^{\circ}$ and were pinned with nails on the stringers and vertical shores.

(C) Small and large inclined braces were installed under horizontal stringers with closed-form horizontal braces (Figure 11(c)). The small inclined brace was made of wood planks $(50 \mathrm{~cm} \times$ $6 \mathrm{~cm}$ ) installed under the horizontal stringers. These two wooden planks were fixed by nails to the horizontal stringers and vertical wooden shores at an angle of $45^{\circ}$. The large inclined brace was a wooden shore setup diagonally between the horizontal stringers and vertical shores. The setup of the closed-form horizontal braces was the same as that for (Figure 7).

(D) A V-shaped large inclined brace structure was considered. These reinforced V-shaped inclined braces were installed between tubes 1,2, and 3 and tubes 5, 6, and 7 of the double-layer shoring system (Figure 11(d)). The lateral supports were setup on two sides of the system. 


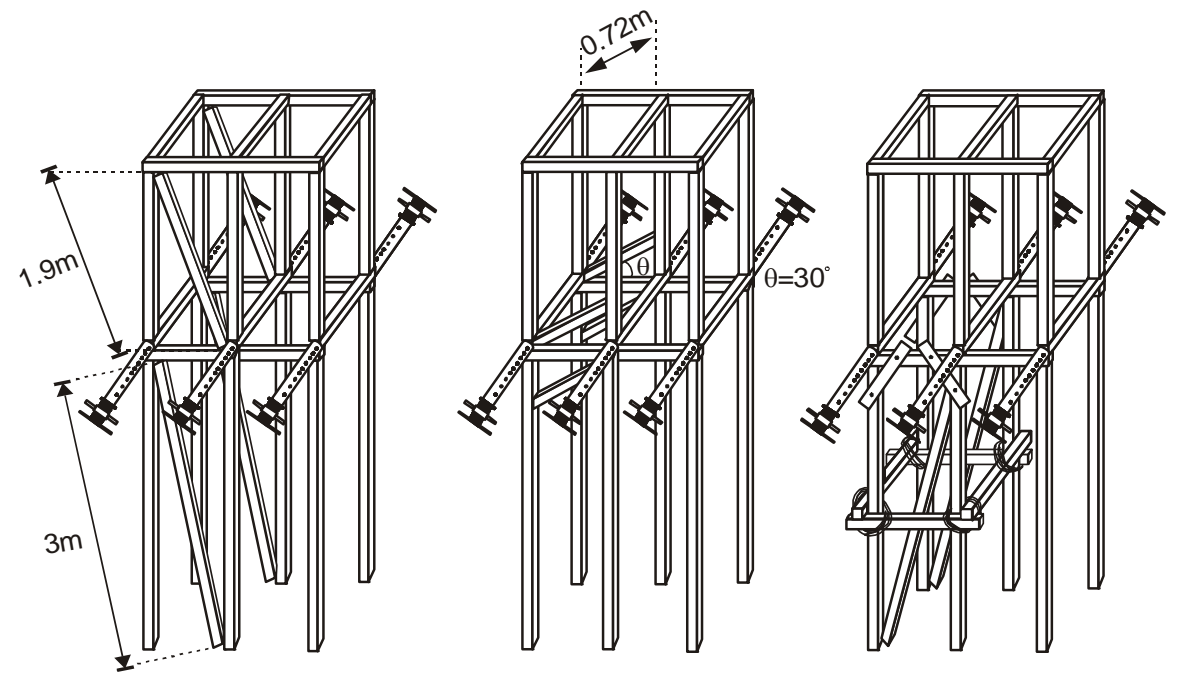

(a) Large inclined braces (b) Small inclined braces

(c) Small \& large inclined braces

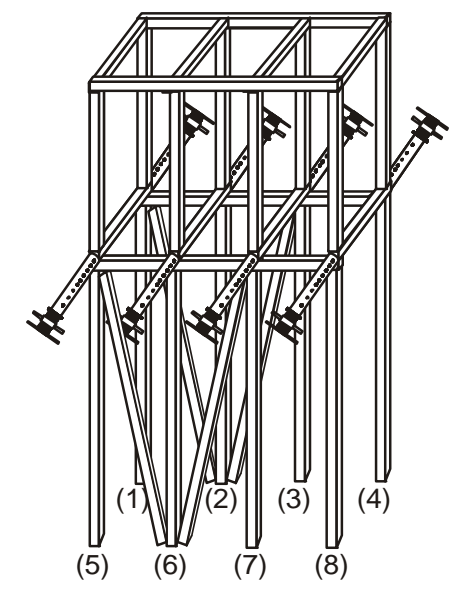

(d)V-shaped reinforcement

Figure 11. Arrangements of Double-layer Shoring Systems with Top and Bottom inclined Bracing Reinforcements

\section{TEST RESULTS AND DISCUSSION}

\subsection{Load Capacity of Isolated Wooden Shore}

The wooden shores were stored at room temperature (roughly $28-30^{\circ} \mathrm{C}$ ) for 3 days before tests. Since water content has a considerable influence on the mechanical properties of wooden shores, it is advisable to reach a steady state for water content to avoid the generation of inaccurate test results. Two tests were conducted for the $3-\mathrm{m}$ wooden shores. In test I, load capacity is $28.2 \mathrm{kN}$, that in test II is $20.94 \mathrm{kN}$, and average load capacity is $24.57 \mathrm{kN}$. Although the two test capacities are insufficient to fully represent load capacity of isolated wooden shores due to the large variability of wood, test results are very close to the load capacity of Kapur when compared with results obtained by previous studies [18]. Thus, these tests can serve as a reference for follow-up tests.

\subsection{Effects of Lateral Supports}

Table 1 shows test results for load capacities of double-layer shoring systems with and without lateral supports. For the double-layer shoring system without lateral supports, the load capacity in test I is $1.36 \mathrm{kN}$, that in test II is $1.19 \mathrm{kN}$, and average load capacity is $1.28 \mathrm{kN}$. The failure model indicates that the joint layer of horizontal stringers tilts gradually on the in-plane direction, generating a continuous and slow lateral displacement. However, no displacement exists at the top and bottom ends, indicating that the horizontal stringer is the weak point in the shoring system. Figure 12(a) presents test results. Figure 13 shows the P- $\Delta$ curve of test II, where P is the vertical load, and $\Delta$ is the horizontal displacement of the horizontal stringer. The tested load capacity is approximately $1.19 \mathrm{kN}$. 


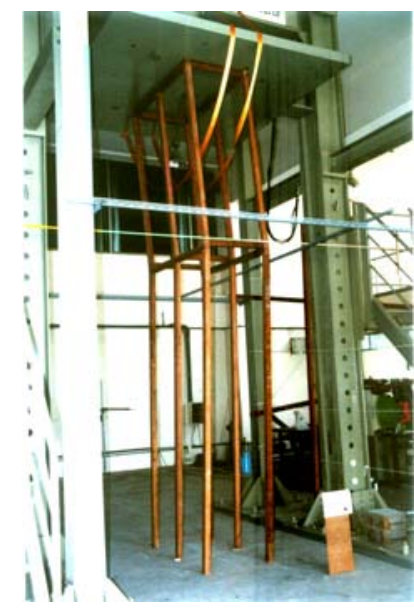

(a) No supports

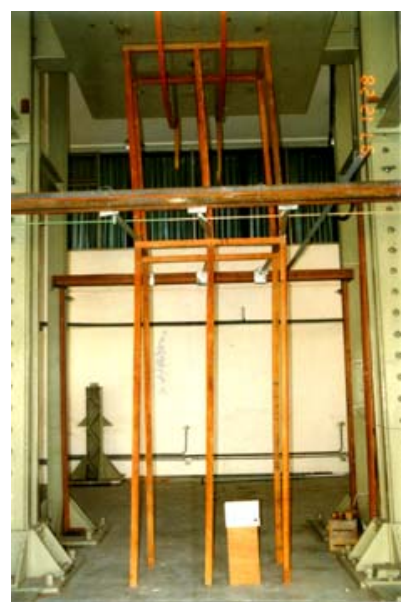

(b) Lateral supports on two sides

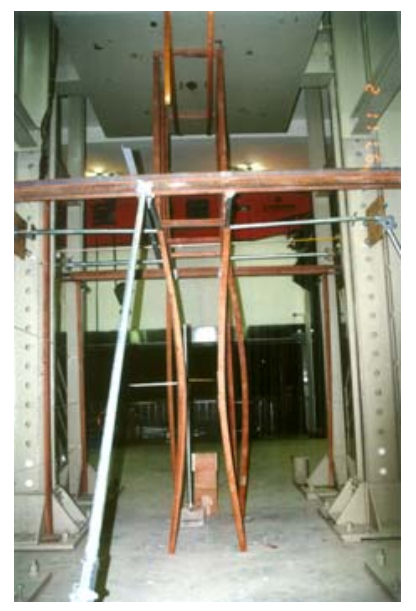

(c) Lateral supports on four sides

Figure 12. Test Results on Double-layer Shoring Systems with and without Lateral Supports

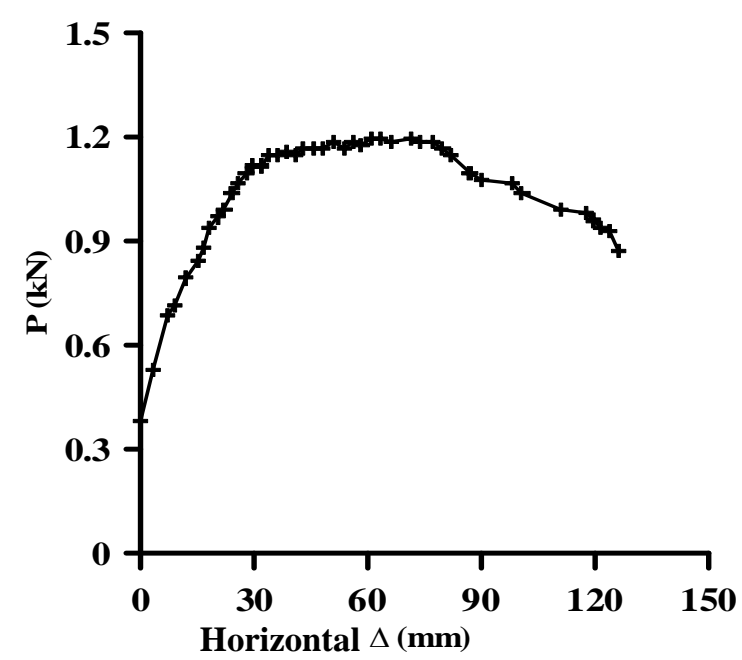

Figure 13. P- $\Delta$ Curve of Test II on Double-layer Shoring System without Lateral Supports

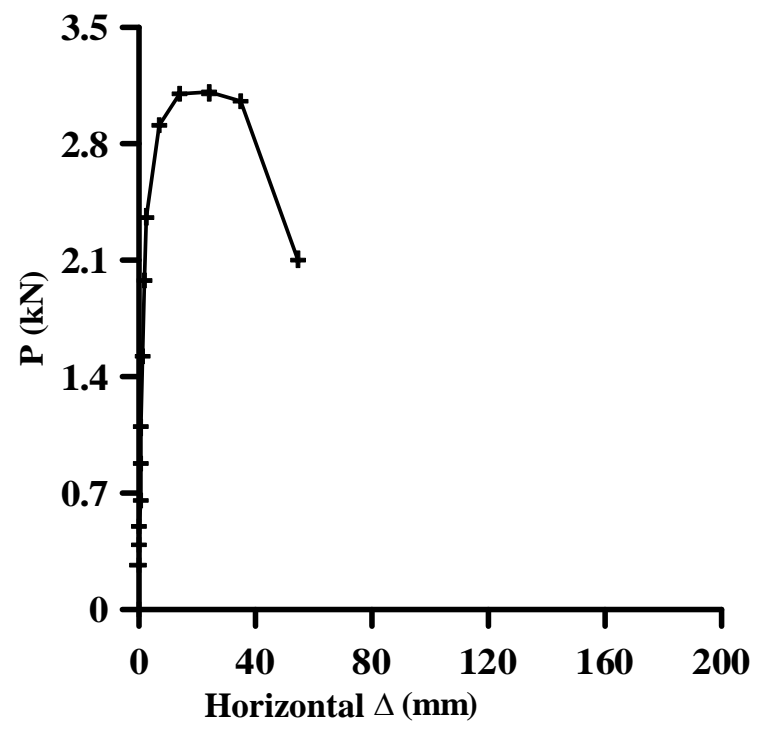

Figure 14. P- $\Delta$ Curve of Test I on Double-layer Shoring System with Lateral supports on Two Sides 
For the double-layer shoring system with lateral supports on two sides, the supports were only set on the in-plane to force the failure of the shoring structure to occur on the out-of-plane. Figure 4 presents definitions for in-plane and out-of-plane. Figure 12(b) shows test results. The load capacity in test $\mathrm{I}$ is $3.23 \mathrm{kN}$, that in test II is $1.54 \mathrm{kN}$, and average load capacity is $2.38 \mathrm{kN}$. The $\mathrm{P}-\Delta$ curve (Figure 14) for test I is close to a vertically straight line before the load reaches $1.74 \mathrm{kN}$, indicating that the initial imperfection of the shoring system is extremely small. The maximum load is 3.23 $\mathrm{kN}$ when the shoring system fails.

The 8-post double-layer shoring systems on the top and bottom with lateral supports on two sides were also tested. The load capacity in test I is $2.17 \mathrm{kN}$, that in test II is $5.94 \mathrm{kN}$, and that in test III is $2.88 \mathrm{kN}$ (Table 1). Average load capacity is $3.66 \mathrm{kN}$. A comparison of test results for the 8-post double-layer shoring system with those for the 6-post double-layer shoring system indicates that the shoring system with lateral supports on one side only does not have sufficient load capacity, and the extension of the shoring system (i.e., adding wooden shores) does not necessarily increase the load capacity of these two double-layer shoring systems.

For the double-layer shoring system with lateral supports on four sides, the longitudinal and latitudinal directions were set with supports to make the shoring system bear lateral forces from two axial directions. In the test, the lateral deflections at the stringer, $\Delta 2$, and at the wooden shore (tube 1), $\Delta 1$, were measured. The lateral deflection $\Delta 1$ of wooden shores is lager than that of stringer $\Delta 2$ (Figure 15). The load capacity in test I is $81.78 \mathrm{kN}$, that in test II is $84.06 \mathrm{kN}$, that in test III is $101.26 \mathrm{kN}$, and the average load capacity is $89.03 \mathrm{kN}$ (Table 1). Figure 12(c) presents test results.

Clearly, in the case of double-layer shoring systems with lateral supports on four sides, average load capacity of the 6-post shores at the top and bottom is $89.03 \mathrm{kN}$ (Table 1), which is $40 \%$ less than total load capacity of the $3-\mathrm{m}$ isolated wooden shore times $6(24.57 \times 6=147.42 \mathrm{kN})$. The load capacities of the double-layer shoring systems without lateral supports or with lateral supports on two sides are much lower than those of the shoring system with lateral supports along four sides. We infer that the main cause of collapse of the double-layer shoring system is due to insufficient lateral support. It means that unless a double-layer shoring system is sufficiently reinforced with lateral supports on four sides, system load capacity decreases substantially and the possibility of collapse is high.

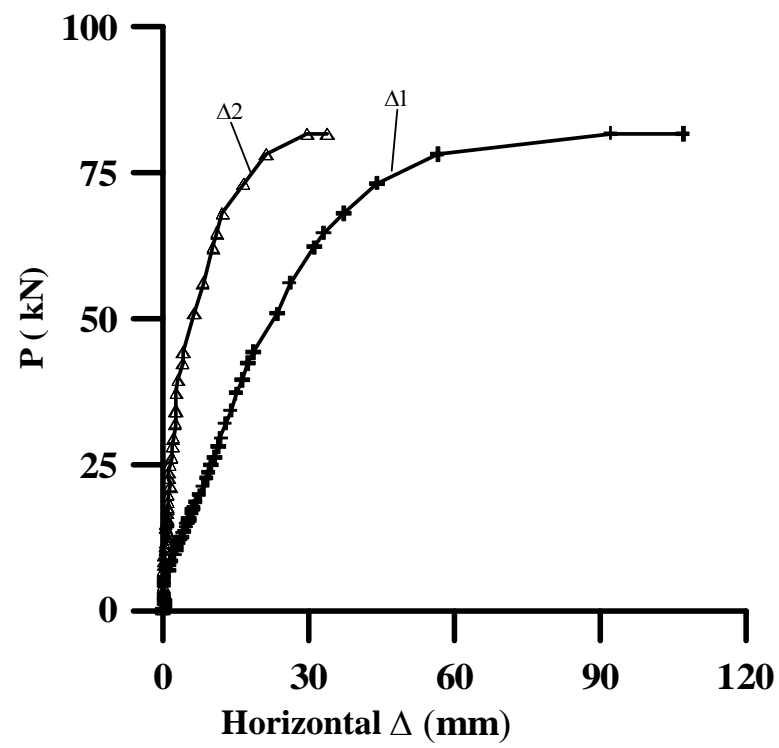

Figure 15. P- $\Delta$ Curve of Test I on Double-layer Shoring System with Lateral supports on Four Sides 
Table 1. Comparison of Load Capacities of Double-layer Shoring Systems with Various Lateral Supports

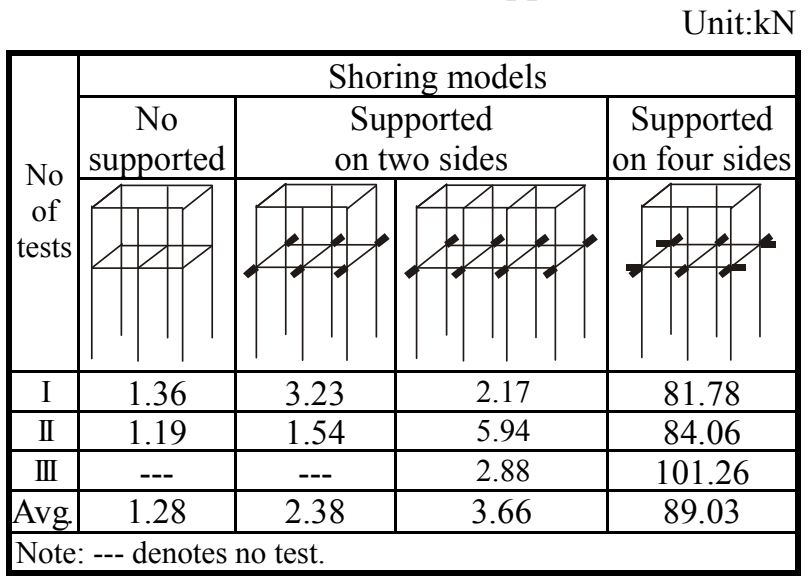

\subsection{Effect of Joint Forms of Horizontal Stringers}

This study considers three connection forms: single butt, single overlap and double overlap. Table 2 shows test results for horizontal stringers with different connection forms in double-layer shoring systems with lateral supports along four sides.

\section{(A) Single butt}

Two tests were conducted on this single butt. The load capacities in tests I and II are $77.21 \mathrm{kN}$ and $76.34 \mathrm{kN}$, respectively. Average load capacity is $76.77 \mathrm{kN}$. This single butt connection on the horizontal stringers provides a good force transmission when lateral supports exist on the four sides. Failure is located on the bottom story of the double-layer shoring system as the bottom shores are longer than the top shores (Figure 16(a)). This is because the horizontal stringer is changed form a sideway case to a non-sideway case.

As shown by the P- $\Delta$ curve (Figure 17), minus-displacement does not occur in the initial stage of the test. This curve is close to a vertically straight line before the load reaches $39.23 \mathrm{kN}$. When the load exceeds $39.23 \mathrm{kN}$, lateral displacement of the bottom-story wooden shore occurs gradually. The shoring system failed when lateral displacement reached $4.8 \mathrm{~cm}$.

\section{(B) Single overlap}

Three tests were conducted for a horizontal stringers overlapping once in the double-layer shoring system. The load capacity in test I is $99.72 \mathrm{kN}, 70.58 \mathrm{kN}$ in test II, $20.83 \mathrm{kN}$ in test III is, and average load capacity is $63.71 \mathrm{kN}$ (Table 2 ).

When the single overlap was adopted at the joints of horizontal stringers, two failure models occurred due to the influence of the initial leaning direction of shoring members. This implies that the shores may be installed leaning toward or away from the overlap position. When the initial lean of all shoring members is away from the overlap position-mode 1 - the load capacity of the shoring system is approximately $85.15 \mathrm{kN}(=(99.72+70.58) / 2)$. Conversely, when the initial lean of all shoring members is toward the overlap position-mode 2-the load capacity of the shoring system is roughly $20.83 \mathrm{kN}$. Figure $16(\mathrm{~b})$ presents test results for failure mode 2 . On construction sites, shores in a double-layer shoring system with a single overlap should be installed on the basis of mode 1 . 


\section{(C) Double overlaps}

Two tests were performed for the case in which horizontal stringers overlap twice in the double-layer shoring system. The load capacity in test I is $51.50 \mathrm{kN}$, that in test II is $34.13 \mathrm{kN}$, and average load capacity is $42.82 \mathrm{kN}$ (Table 2 ).

When the double overlap technique was adopted at the joints of horizontal stringers, two failure modes occurred due to the initial lean of shoring members, as in the case of a single overlap. When the initial lean of all shoring members is away from the overlap position (mode 1), load capacity of the shoring system is roughly $51.50 \mathrm{kN}$. Conversely, when the initial lean of all shoring members moves toward the overlap position (mode 2), load capacity of the shoring system is about $34.13 \mathrm{kN}$. Figure 16(c) shows test results for mode 1. When the double overlap scheme was adopted at the joints of horizontal stringers, average load capacity of the double-layer shoring system was approximately $30 \%$ less than the case when the single overlap technique was adopted $((63.71-42.82) / 63.71 \times 100 \%=32.8 \%)$.

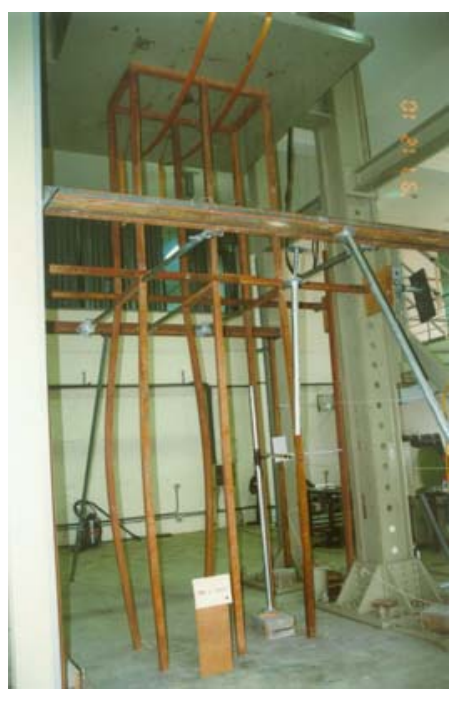

(a) Single butt

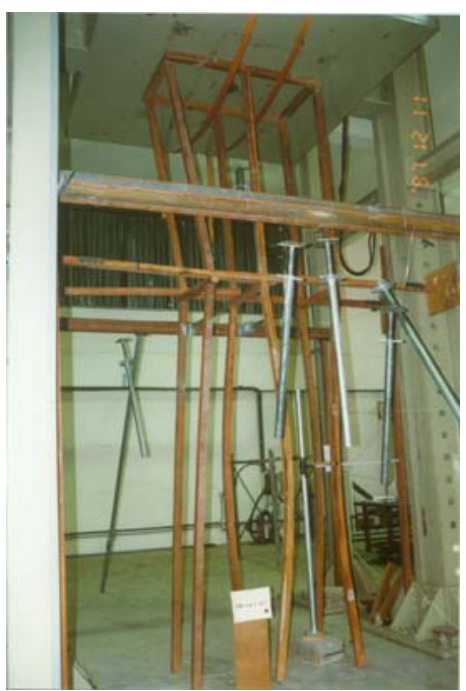

(b) Single overlap

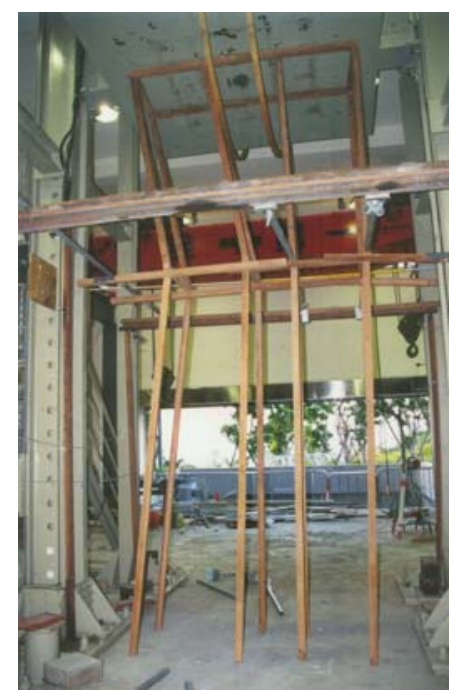

(c) Double overlap

Figure 16. Test Results on Double-layer Shoring Systems with Varied Joint Forms of Horizontal Stringers

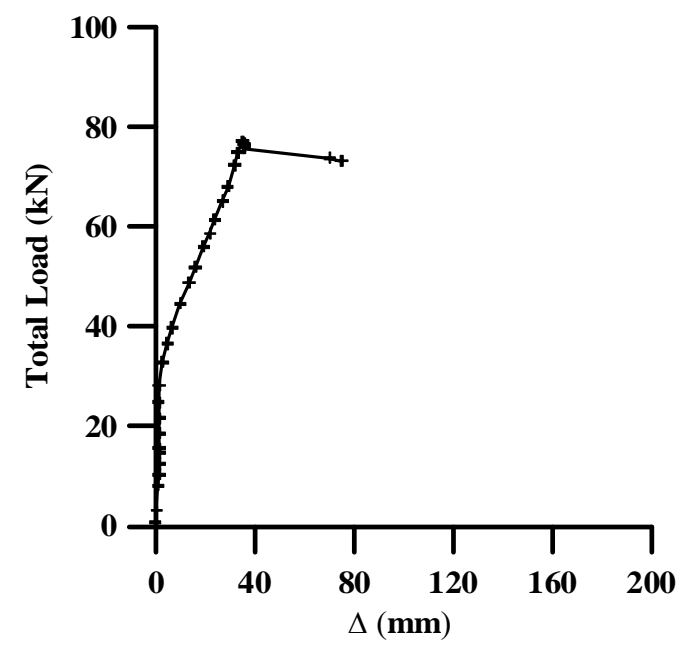

Figure 17. P- $\Delta$ Curve of Test I on Double-layer Shoring System with Single Butt for Horizontal Stringers 
The case of the single butt has the largest load capacity, followed by the single overlap (Table 2). The double overlap scheme has the lowest load capacity. The failure modes of the single overlap and double overlap schemes are very similar. In both cases, shoring members tend to displace toward the location of the overlap position after loading, resulting in systematic failure of the double-layer shoring system. We assume that regardless of whether the single overlap or double overlap scheme is adopted, as long as the initial lean of shoring members is toward the overlap position, the shoring system is likely to collapse as its load capacity is reduced. We recommend adopting the single butt technique, instead of single or double overlaps, when connecting horizontal stringers to a double-layer shoring system to facilitate a direct transfer of axial horizontal forces.

Table 2. Comparison of Load Capacities of Double-layer Shoring Systems with Varied Joint Forms of Horizontal Stringers

Unit:kN

\begin{tabular}{|c|c|c|c|}
\hline \multirow{4}{*}{$\begin{array}{c}\text { No. } \\
\text { Nof } \\
\text { tests }\end{array}$} & Single butt & $\begin{array}{c}\text { Single } \\
\text { overlap }\end{array}$ & $\begin{array}{c}\text { Double } \\
\text { overlap }\end{array}$ \\
\cline { 2 - 4 } & & \\
\hline I & 77.21 & 99.72 & 51.50 \\
\hline II & 76.34 & 70.58 & 34.13 \\
\hline III & --- & 20.83 & --- \\
\hline Avg. & 76.77 & 63.71 & 42.82 \\
\hline Note: --- denotes no test. \\
\hline
\end{tabular}

\subsection{Effect of Horizontal Braces}

Figure 7 shows the setup of the rectangular hollow closed-form horizontal braces, which are commonly used in construction sites in Taiwan. The horizontal stringers move after loading (Figure 18). The overall structure displaces progressively toward the in-plane direction after loading. Figure 19 shows the P- $\Delta$ curve.

Test results (Table 3) indicate that load capacity of the shoring system with lateral supports on two sides and with the rectangular hollow closed-form horizontal braces is similar to that of the shoring system without closed-form horizontal braces (Figure 12(b)). This implies that on construction sites, setting up rectangular hollow closed-form horizontal braces on wooden shores does not increase significantly the load capacity of the double-layer shoring system.

The expected reinforcement effect does not occur after horizontal braces are installed in the double-layer shoring system. This may be because workers tie wires around the horizontal braces to resist bending moments and to resist lateral displacement. However, since wire strength is relatively small, when the wires become loose after loading, their anti-bending moment declines markedly. Therefore, when rectangular hollow closed-form horizontal braces are only tied up on the bottom story of the shoring system, they cannot increase system load capacity. However, further investigation is needed for such reinforcement. 


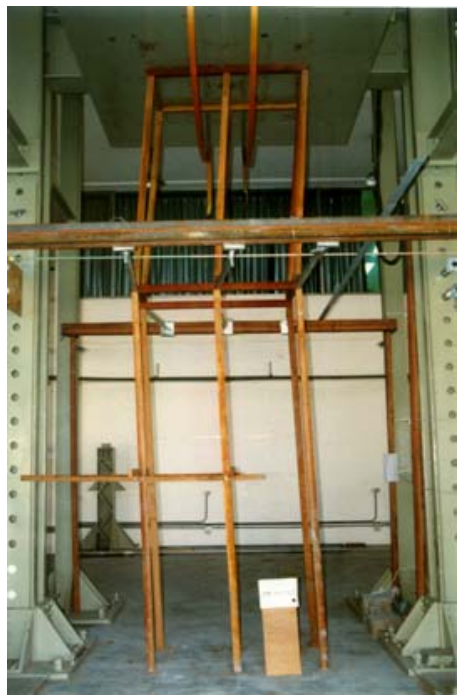

Figure 18. Test Results on Double-layer Shoring System with Horizontal Braces

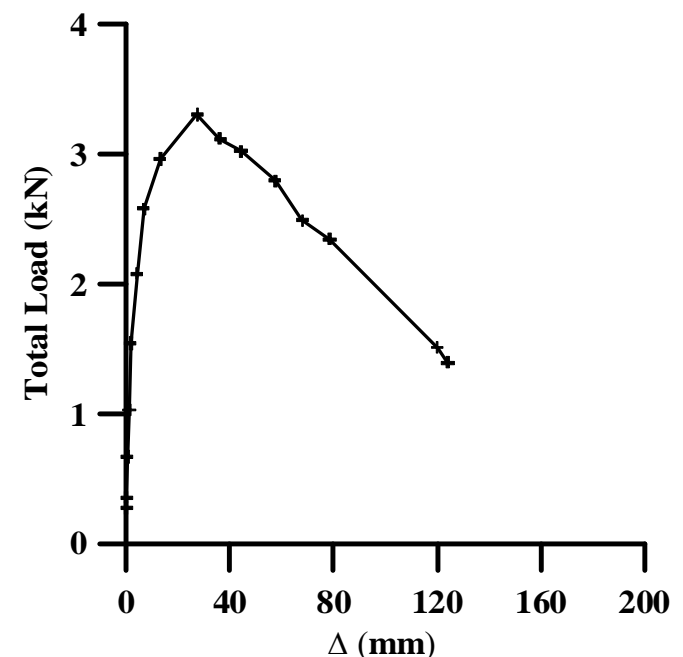

Figure 19. P- $\Delta$ Curve of Test I on Double-layer Shoring System with Horizontal Brace Reinforcement

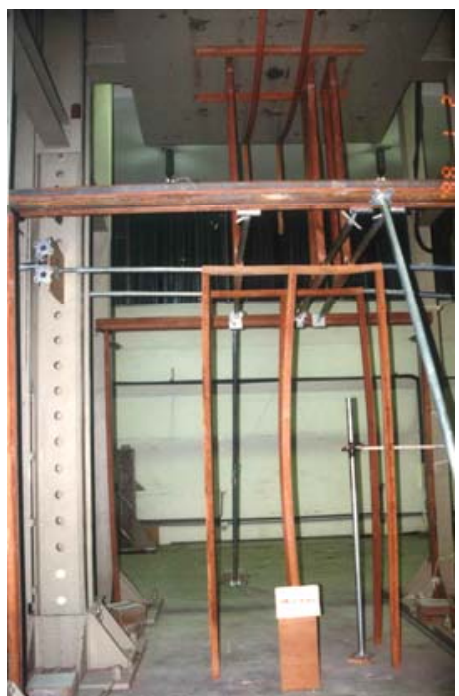

Figure 20. Test Results on Double-layer Shoring System with Axial Force Indirect Transfer 
Table 3. Comparison of Load Capacities of Double-layer Shoring Systems with and without Horizontal Braces

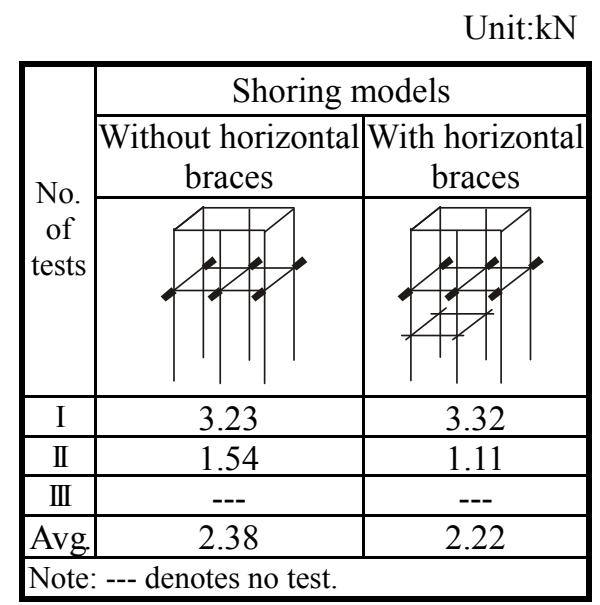

\subsection{Effect of Eccentric Loads on Shores}

Test results demonstrate that when vertical shores at the top and bottom stories do not contact directly, the load capacity in test I is $80.68 \mathrm{kN}$, that in test II is $89.87 \mathrm{kN}$, and the average load capacity is $85.27 \mathrm{kN}$, which is close to the average load capacity of $89.03 \mathrm{kN}$ when the vertical shores at the top and bottom stories are symmetrical (Figure 5(c)).

Figure 8 shows the test setup with four lateral supports fastened on four sides respectively. Figure 20 shows the test results after loading. When loading starts, the bottom wooden shore buckles first, and then the horizontal stringers parallel to the in-plane and out-of-plane surfaces bend progressively. As soon as the shore, tube 4, at the bottom wooden shore broke, the overall structure collapsed instantly.

The P- $\Delta$ curve in Figure 21 shows an unstable increasing trend. It is likely because the force applied to the wooden shore is non-uniform and constantly changing, causing the wooden shores and horizontal stringers to deform. Test results demonstrate that the horizontal stringers provide considerable load capacity when they bear the bending moment caused by the asymmetrical topand bottom-story wooden shores. In terms of construction-site safety, adopting a double-layer shoring system with asymmetrical top- and bottom-story wooden shores is inadvisable.

\subsection{Effect of Inclined Boundaries}

Table 4 lists the test results for the double-layer shoring system with a $20^{\circ}$ inclination relative to the ground. The load capacity in test I is $124.74 \mathrm{kN}$, that in test II is $113.76 \mathrm{kN}$, and the average load capacity is $119.25 \mathrm{kN}$. Figure 9 shows the test setup of the shoring system with lateral supports on four sides. During the test, the wooden shores started deforming slightly toward the in-plane direction under loading. Notably, tubes 4 and 5 buckle; that is, as loading increases, the deformation of tubes 4 and 5 increases until they buckle successively. Figure 22 shows test results. Figure 23 shows the P- $\Delta$ curve for the double-layer shoring system with a $20^{\circ}$ inclination relative to the ground. 
The average load capacity of the double-layer shoring system with a non-inclined surface and lateral supports on four sides is $89.03 \mathrm{kN}$ (Figure 12(c)). Load capacity, $119.25 \mathrm{kN}$, of the double-layer shoring system with a $20^{\circ}$ inclination relative to the ground, is $25 \%$ higher than others in the double-layer shoring system with the flat ground $((119.25-89.03) / 119.25=25.3 \%)$. This is mainly because some wooden shores of the former system are shorter than those of the latter system. Thus, the short wooden shores have small effective length and provide higher critical loads for the system. Based on test results, we infer that for a double-layer shoring system with lateral supports on four sides, the effect of effective length on load capacity is larger than that of the system on an inclined ground.

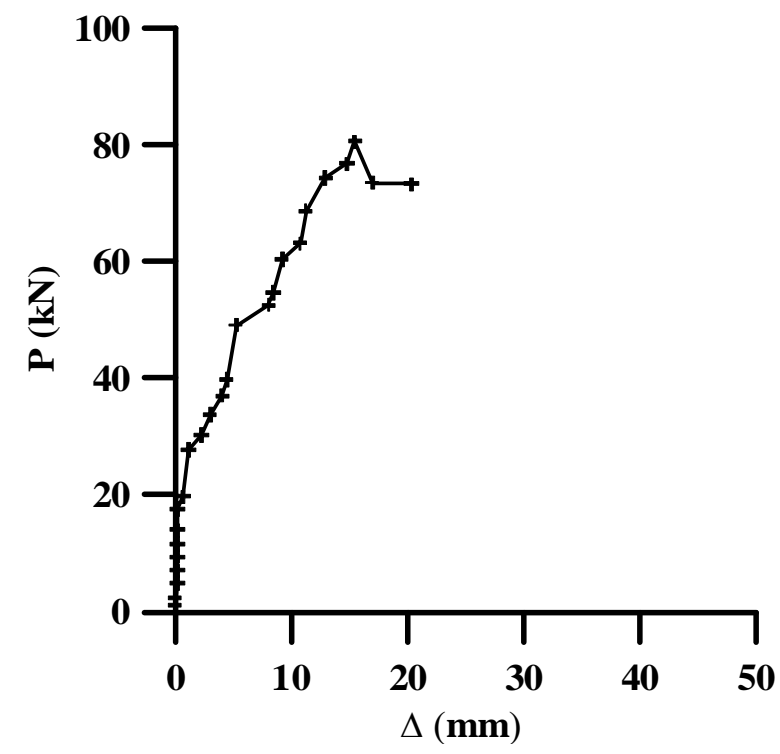

Figure 21. P- $\Delta$ Curve of Test I on Double-layer Shoring System with Axial Force Non-direct Transfer

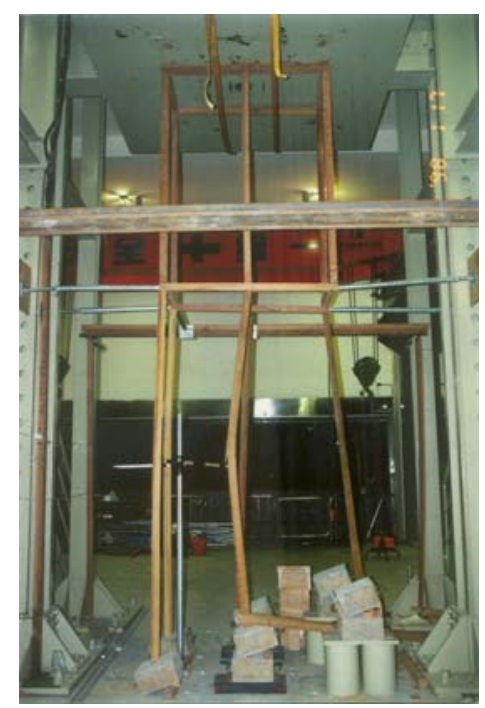

Figure 22. Test Results on Double-layer Shoring System with Inclined Boundary Condition 


\subsection{Combination of Wooden Shores and Steel-tube shores}

Three tests were conducted for the double-layer shoring system with top wooden shores and bottom adjustable steel-tube shores with lateral supports on four sides. As the load capacity in test I is $168.36 \mathrm{kN}$, that in test II is $123.34 \mathrm{kN}$, and that in test III is $123.51 \mathrm{kN}$, the average load capacity is $138.40 \mathrm{kN}$ (Table 4).

Figure 24 shows the test results for test I. This test shows the buckling failure of some adjustable steel-tube shores in the system. As loading increases, the top-story wooden shores and bottom-story adjustable steel-tube shores deform. When the shoring system collapsed, the bottom-story adjustable steel-tubes buckled (Figure 24), indicating that the load capacity of top-story wooden shores exceeds that of bottom adjustable steel-tube shores. Additionally, the load capacity (138.40 $\mathrm{kN}$ ) of the double-layer shoring system with top-story wooden shores and bottom-story adjustable steel-tube shores is larger than that $(89.03 \mathrm{kN})$ of the shoring system with wooden shores on both the top and bottom stories (Table 4).

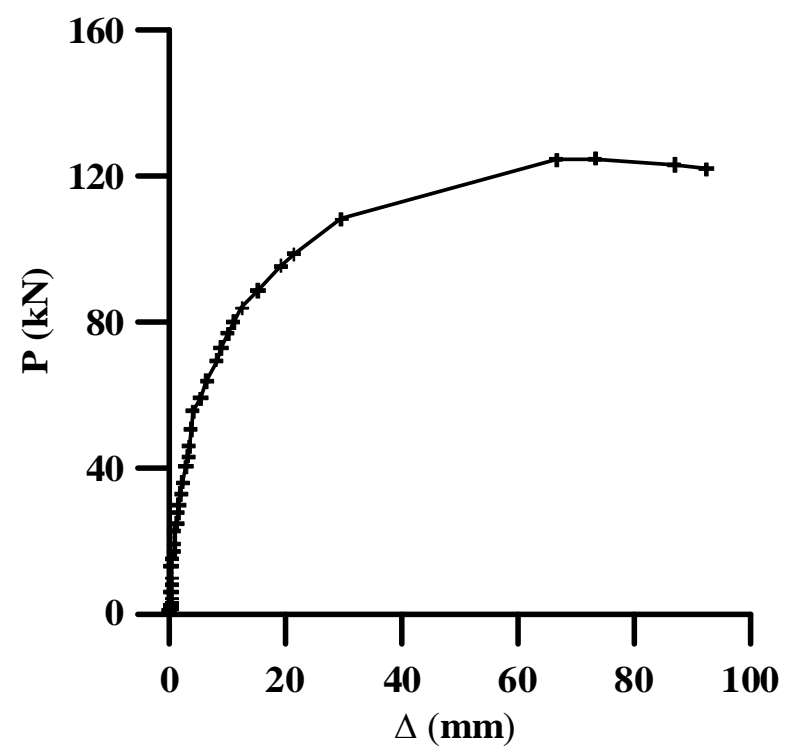

Figure 23. P- $\Delta$ Curve of Test I on Double-layer Shoring System with Inclined Boundary Condition

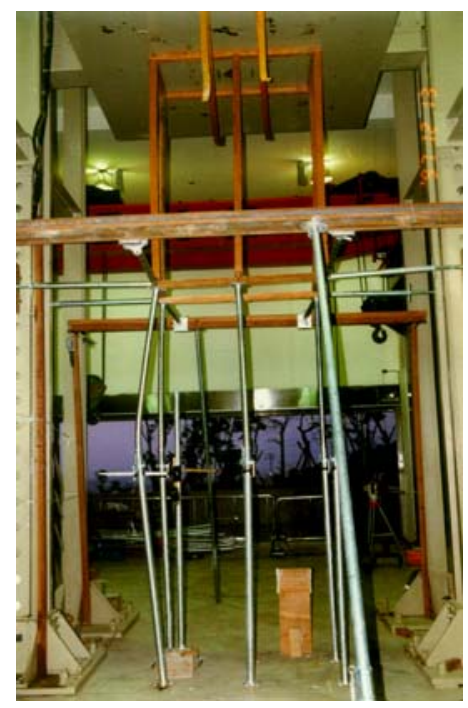

Figure 24. Test Results on Double-layer Shoring System with Combined Setup of Shores 
Table 4. Comparison of Load Capacities of Double-layer Shoring Systems with Different Installations

\begin{tabular}{|c|c|c|c|c|}
\hline \multirow{4}{*}{$\begin{array}{c}\text { No. } \\
\text { of } \\
\text { tests }\end{array}$} & $\begin{array}{c}\text { Supported } \\
\text { on four } \\
\text { sides }\end{array}$ & $\begin{array}{c}\text { Axial force } \\
\text { non-direct } \\
\text { transfer }\end{array}$ & $\begin{array}{c}\text { Inclined 20 } \\
\text { to the gound }\end{array}$ & $\begin{array}{c}\text { Combined use of } \\
\text { wooden shore and } \\
\text { adjustable steel } \\
\text { tube shore }\end{array}$ \\
\hline I & 81.78 & 80.68 & 124.74 & 168.36 \\
\hline II & 84.06 & 89.87 & 113.76 & 123.34 \\
\hline III & 101.26 & --- & --- & 123.51 \\
\hline Avg & 89.03 & 85.27 & 119.25 & 138.40 \\
\hline Note: --- denotes no test. & & \\
\hline
\end{tabular}

\subsection{Effect of Different Reinforcements}

\subsubsection{Large inclined reinforcement braces on the top and bottom stories}

The load capacities in tests I, II, and II for this reinforcement technique are $84.01 \mathrm{kN}, 111.62 \mathrm{kN}$ and $107.25 \mathrm{kN}$, respectively, and average load capacity is $100.96 \mathrm{kN}$. At the early stage in each of the three tests, the double-layer shoring system was only slightly displaced. This was followed by constant creaking noises, which we inferred to be the noise made by nails being gradually pulled out when resisting the lateral displacement of the overall shoring structure.

As shown in Table 1 and Table 5, the load capacity with this reinforcement technique increases to roughly 42 times $(=100.96 / 2.38)$ that of the non-reinforced scheme. This is because the inclined reinforcement braces can make the horizontal stringers from the sideway case to the non-sideway case. Thus, the inclined reinforcement braces change the failure mode from system buckling to member buckling (Figure 25(a)).

\subsubsection{Small inclined reinforcement braces on the top and bottom stories}

The load capacities in these two tests are $24.84 \mathrm{kN}$ and $22.02 \mathrm{kN}$, and average load capacity is $23.43 \mathrm{kN}$ (Table 5). At the start of this test, the horizontal stringers showed very minute displacements. Over time, the nails fastening the small inclined braces to the top and bottom stories gradually pulled out. As loading continued and reached the load capacity, the overall double-layer shoring system failed due to marked horizontal displacement (Figure 25(b)).

The load capacities illustrated in Table 1 and Table 5 indicate that this reinforcement case is roughly 10 times $(=23.43 / 2.38)$ that of the non-reinforced case. Compared with the setup with large inclined braces, the two ends of the large inclined bracings are diagonally shored up the ground and horizontal stringers, respectively, which are considered more rigid. Thus, the large inclined braces strengthen to the overall double-layer shoring system. Conversely, because the two ends of the small inclined bracings shore up the wooden shores and horizontal stringers, respectively, and are pinned with nails, the ability of the nails is not sufficient to withstand the lateral displacement of the horizontal stringers. Although the load capacity of small inclined braces for both top and bottom stories is not comparable to that of large inclined braces, the required material for this reinforcement method is considerably reduced. 
Table 5. Comparison of Load Capacity of Double-layer Shoring Systems with Varied Reinforcement Configurations

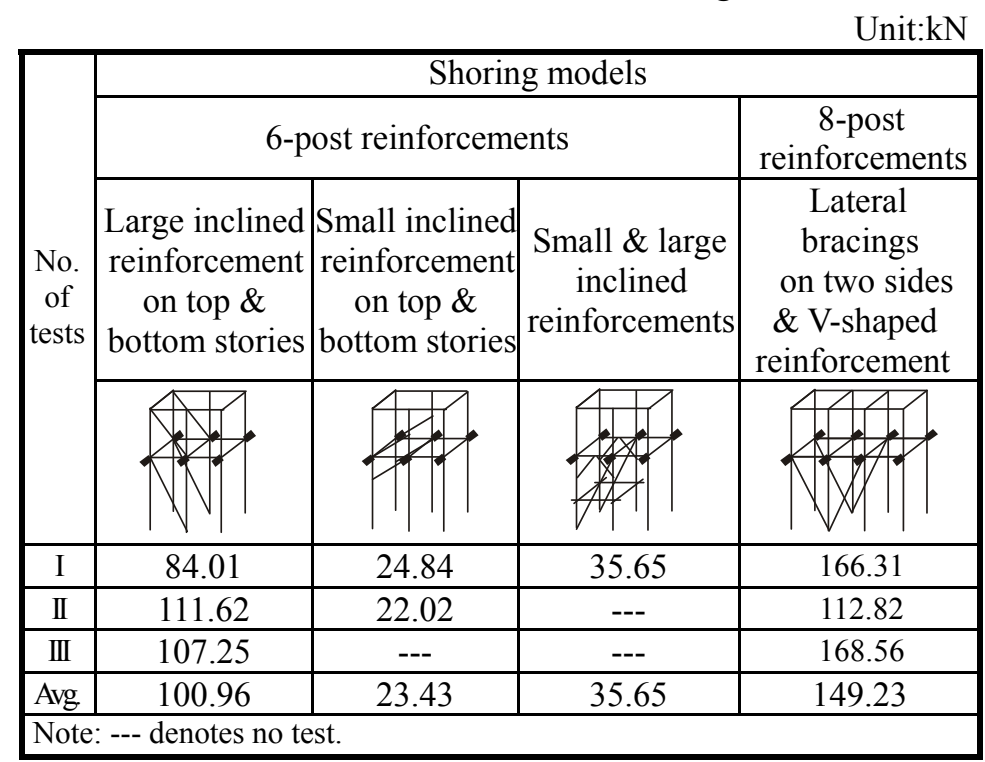

\subsubsection{Small and large reinforcement braces with closed-form horizontal braces}

The tested load capacity of the small and large reinforced inclined braces with closed-form horizontal braces is $35.65 \mathrm{kN}$ (Table 5). As the shoring materials required to complete this test were insufficient, only one test for this reinforcement case was considered in this study. This test is the final one.

In this test, minor lateral displacement of the overall system appeared first. However, the displacement was gradually replaced by the inclined reinforcement braces. The reinforced brace deformed toward the in-plane direction and finally buckles. Figure 25(c) shows the test result.

Comparison of the load capacities in Table 1 and Table 5 indicates that the load capacity of this reinforcement scheme is approximately 15 times $(=35.65 / 2.38)$ that of the non-reinforced case. This implies that this reinforcement scheme can increase the load capacity of double-layer shoring systems. However, the final failure mode is still system buckling (Figure 25(c)).

\subsubsection{V-shaped large inclined reinforcement braces}

The load capacities in three tests for this reinforcement technique are $166.31 \mathrm{kN}, 112.82 \mathrm{kN}$, and $168.56 \mathrm{kN}$, and average load capacity is $149.23 \mathrm{kN}$ (Table 5). Figures 11(d) and 26(a) show the installation before loading. After loading, the double-layer shoring system displaced gradually in the in-plane direction. Subsequently, some inclined reinforcement braces shored on the horizontal stringers deformed. Finally, one inclined strengthening brace buckled. This causes other inclined reinforcement shores to fall and the double-layer shoring system then becomes considerably displaced and finally collapses (Figure 26(b)).

For the setup of a V-shaped large inclined reinforcement braces (Figures 11(d) and 26(a)), the load capacity of this reinforcement scheme is about 41 times $(=149.23 / 3.66)$ that of the non-reinforced 8-post case (Table 1). The load capacity of this V-shaped reinforced installation is close to that of case (A) with inclined reinforcement braces on simpler top and bottom stories. However, installation of these reinforced shores in case (D) is easier than that in case (A) on construction sites since workers only need to install strengthening braces on the bottom story. 


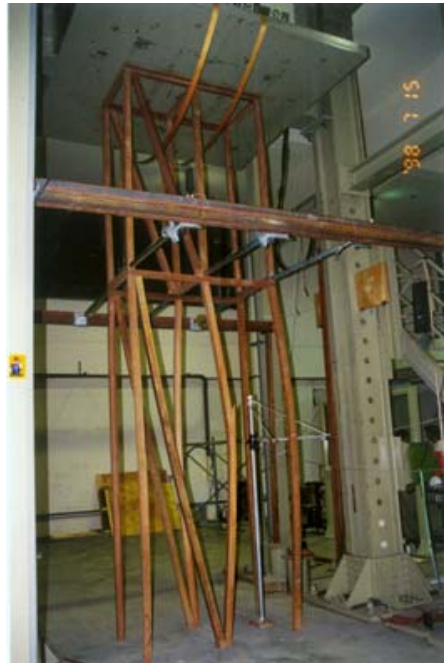

(a) Large inclined reinforcement

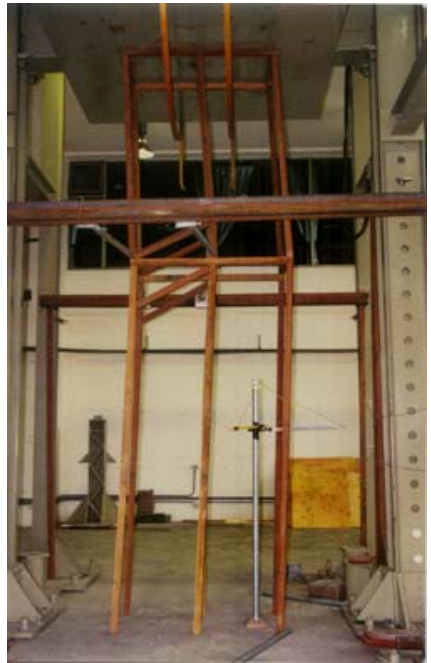

(b) Small inclined reinforcements

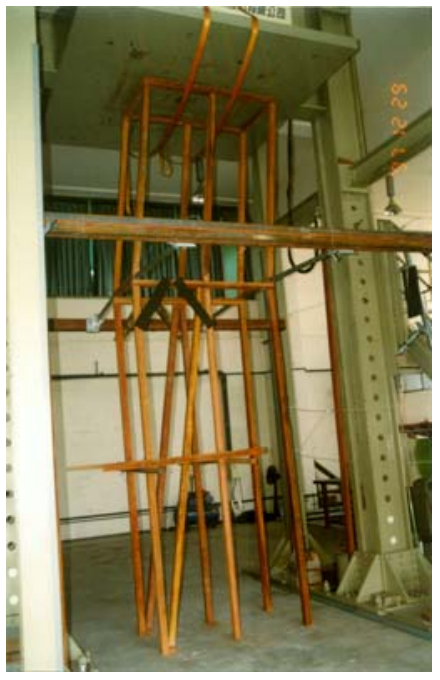

(c) Small \& large reinforcements

Figure 25. Test Results on 6-post Double-layer Shoring Systems with Different Reinforcements

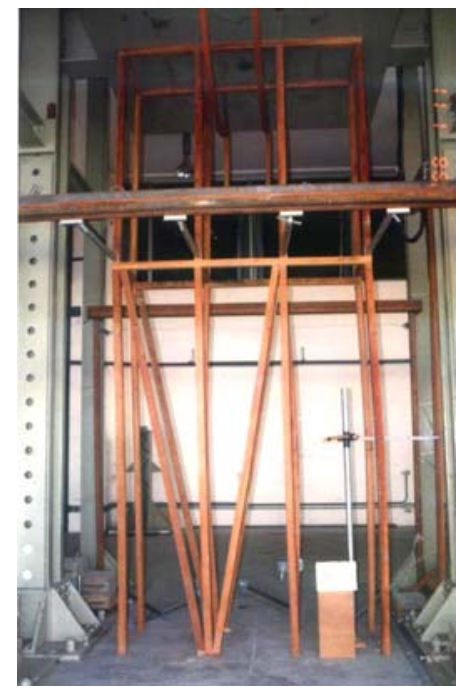

(a) V-shaped inclined braces before loading

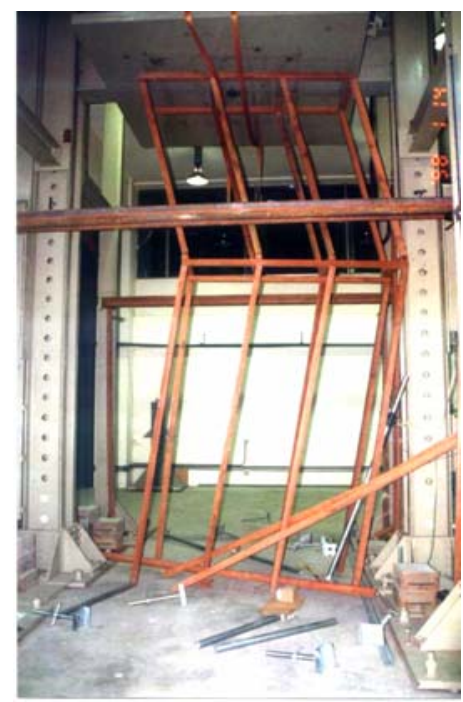

(b) V-shaped inclined braces after loading

Figure 26. Test Results on V-shaped Reinforcement Braces in Double-layer Shoring System

\section{CONCLUSIONS}

1. The failure of the double-layer shoring systems shows that horizontal stringers tilt in the direction without lateral supports when no displacement is present at the top and the bottom. This indicates that the horizontal stringer is the weak point in the double-layer shoring system. 
2. The collapse of a double-layer shoring system is mainly caused by insufficient lateral supports on the horizontal stringers. Therefore, the lateral supports on four sides at the positions of horizontal stringers must be setup to prevent shoring systems from collapsing.

3. Different joints for the horizontal stringers significantly change the load capacity. The single butt has the highest load capacity. The failure modes of single and double overlaps are very similar. For single or double overlaps, the shoring system collapses under a low load capacity when the initial leaning of shoring members is toward the overlap position. We recommend utilizing the single butt for connecting horizontal stringers in a double-layer shoring system.

4. Reinforcing the join between rectangular hollow closed-form horizontal braces and vertical wooden shores using steel wire only at the bottom story does not enhance the load capacity of double-layer shoring systems. Reinforcing these horizontal braces cannot replace reinforced lateral supports at horizontal stringers.

5. The horizontal stringers provide considerable load capacity, even when stringers bear the bending moment caused by asymmetrical top- and bottom-story wooden shores. However, failure is sudden and drastic. In consideration of construction site safety, we advise that the asymmetrical top- and bottom-story wooden shores in a double-layer shoring system should not be used.

6. For the lateral supports on four sides of a double-layer shoring system, the inclination ground of the double-layer shoring system does not apparently impair tested load capacities.

7. The load capacity of the double-layer shoring system with a setup combining wooden shores and adjustable steel-tube shores is higher than that of the shoring system using only wooden shores.

8. After comparing the large or small inclined reinforcements on both the top and bottom stories and reinforcement with $\mathrm{V}$-shaped inclined bracings in double-layer shoring systems, we recommend that reinforcement with $\mathrm{V}$-shaped inclined bracings should be utilized to reinforce double-layer shoring systems.

9. If a double-layer shoring system is not well reinforced with lateral supports, simply increasing the number of leaning-column wooden shores does not increase system load capacity significantly. However, falsework workers seldom realize this. This is one of the reasons for the collapse of double-layer shoring systems.

\section{ACKNOWLEDGMENTS}

The authors would like to thank the National Science Council, Taiwan, for financially supporting this research under Project No. NSC 96-2221-E-224-022. Mr. C. M. Kung and W. C. Huang are commended for performing experimental tests. 


\section{REFERENCES}

[1] Institute of Occupational Safety and Health (IOSH); Occupational Accidents Report Construction Industry, Library of IOSH, Council of Labor Affairs, Executive Yuan, 1994. (in Chinese)

[2] Hadipriono, F.C. and Wang, H.C., "Analysis of Causes of Formwork Failures in Concrete Structures", Journal of Construction Engineering and Management, ASCE, 1986, Vol. 112, No. 1, pp. 112-121.

[3] Kao, C.C., "An Investigation on Safety and Usage of Domestic Steel-tube Scaffolds", Taiwan Constructional Research Center, 1983, Report No.TR-7210. (in Chinese)

[4] Leu, L.J., Kao, C.C., Yang, Y.B., Huang, W.H., Huang, M.Y., Tsou, C.H., Wu, S.H. and Lin, C.C., "A Study on the Capacity and Frequency Measurement of Steel Scaffolds", Institute of Occupational Safety and Health Council of Labor Affairs, Taiwan, 1996, Report IOSH85-S126. (in Chinese)

[5] Chan, S.L., Chu, A.Y.T. and Albermani, F.G., "Stability and Simulation-Based Design of Steel Scaffolding without Using te Effective Length Method", Structural Stability and Dynamics, Dec. 2003, Vol. 3, No. 4, pp. 443-460.

[6] Chan, S.L. and Cho, S.H., "Second-Order Analysis and Design of Angle Trusses Part 1: Elastic Analysis and Design", Engineering Structures, 2008a, No. 30, pp. 616-625.

[7] Chan, S.L. and Cho, S.H., "Second-Order Analysis and Design of Angle Trusses Part 2: Plastic Analysis and Design”, Engineering Structures, 2008b, No. 30, pp. 626-631.

[8] Iu, C.K.J. and Chan, S.L., "A Simulation-based Large Deflection and Inelastic Analysis of Steel Frames under Fire", Journal of Constructional Steel Research, 2004, No. 60, pp.1495-1524.

[9] Peng, J.L., Pan, A.D.E., Chen, W.F., Yen, T. and Chan, S.L., "Structural Modeling and Analysis of Modular Falsework Systems", Journal of Structural Engineering, ASCE, 1997, Vol. 123, No. 9, pp. 1245-1251.

[10] Peng, J.L., Pan, A.D., Rosowsky, D.V., Chen, W.F., Yen, T. and Chan, S.L., "High Clearance Scaffold Systems during Construction - I. Structural Modelling and Modes of Failure", Engineering Structures, 1996a, Vol. 18, No. 3, pp. 247-257.

[11] Peng, J.L., Rosowsky, D.V., Pan, A.D., Chen, W.F., Chan, S.L. and Yen, T., "High Clearance Scaffold Systems during Construction - II. Structural Analysis and Development of Design Guidelines", Engineering Structures, 1996b, Vol. 18, No. 3, pp. 258-267.

[12] Mosallam, K. and Chen, W.F., "Design Consideration for Formwork in Multistory Concrete Buildings", Engineering Structures, 1990, Vol. 12, No. 7, pp. 163-172.

[13] El-Shahhat, A.M., Rosowsky, D.V. and Chen, W.F., "Construction Safety of Multistory Concrete Building”, ACI Structural Journal, 1994, Vol. 91, No. 4, pp. 475-485.

[14] Peng, J.L., "Stability Analyses and Design Recommendations for Practical Shoring Systems during Construction", Journal of Construction Engineering and Management, ASCE, 2002, Vol. 128, No. 6, pp. 536-544.

[15] Peng, J.L., "Structural Modeling and Design Considerations for Double-layer Shoring Systems", Journal of Construction Engineering and Management, ASCE, 2004, Vol. 130, No. 3, pp. 368-377.

[16] Lemessurier, W. J., "A Practical Method of Second Order Analysis, Part 2 - Rigid Frames", AISC Engineering Journal, 1977, Vol. 14, No. 2, pp. 49-67.

[17] Chinese National Standard, "Wood-Determination of Compression Properties", (In Chinese) CNS - 453, 2005, No. O2004.

[18] Yen, T., Chen, W.F. and Lin, C.H., "Research of Wooden Shore Strength and Check Lists Using in Construction", (in Chinese) Council of Labor Affairs, Taipei, Taiwan, 1994. 